\title{
Behavioural disabilities in psychogeriatric patients and residents of old people's homes
}

\author{
C. J. GILLEARD
}

From the Department of Psychiatry, University of Edinburgh

\author{
A. H. PATTIE \\ From the Clinical Psychology Department, Clifton Hospital, York
}

\author{
G. DEARMAN
}

From the North Yorkshire Social Services Department

SUMMARY A comparison was made of the behavioural disabilities of two groups of elderly $\stackrel{\curvearrowright}{?}$ institutionalised people, one in psychogeriatric hospital wards and the other in residential homes. $\omega$ The results indicated that despite considerable overlap, there is evidence of significantly greateriv disability in the hospital population, particularly as regards incontinence, confusio communication difficulties, and need for supervision. Comparison with previous data suggests the $\mathrm{f}_{0}$ there is an increasing number of elderly people with such problems in the care of social servicess 5 departments. This trend, if supported and continued, is likely to reduce further the distinction between old people in hospital and those in social services homes, with important implications for future planning of the care and management of the elderly.

The two types of elderly institutionalised populations whose behavioural disabilities we examine in this paper are those admitted to long-stay psychogeriatric wards and those admitted to residential accommodation provided by the social services. Few studies have made any direct comparison of these two populations. Carstairs and Morrison ${ }^{1}$ compared 'elderly' patients in mental hospitals and residents of homes for the elderly in south-west Scotland on broad indices of impairment primarily related to mobility, continence, and mental confusion, but they did not distinguish between 'long-stay' patients - that is, between those patients usually with non-organic diagnoses who have grown old in hospital, and those who have been admitted to hospital after reaching old age: the psychogeriatric patients. It is more relevant, however, to identify which features of disability lead to long-term care in hospital, and to compare them with those which lead to care in old people's homes, among people who have survived in the community before age and its associated pathologies necessitate some degree of institutional care. In the present study, therefore, we have attempted to identify the features of disability that differentiate the elderly in the two types of institution, applying a pre-established measuring instrument of behavioural disability.

\section{Methods}

One-third of the homes for the elderly in North Yorkshire and two of the three major psychiatric $\bar{T}$ hospitals provided the study population, represented by 684 residents in old people's homes and 202. psychogeriatric patients. Ratings for each resident or $\stackrel{\circ}{\circ}$ patient were calculated by senior caring or nursing staff, using the CAPE behaviour rating scale. ${ }^{2}$ There 3 are 18 items covering four principal areas of disability - physical disability, apathy or inactivity, $\stackrel{\circ}{3}$ communication difficulties, and social disturbance. In addition, the behaviour rating score included two 'non-scoring' items on sensory deficits.

\section{Results}

Table 1 shows the levels of disablement in each $N$ institutional population sample and the age $\mathbb{N}^{N}$ distribution of the samples. Each person was rated 0 , 0 1 , or 2 for each item. 
Table 1 Disability levels of psychogeriatric hospital patients and residents of old people's homes as determined by the 18 items of the CAPE behavioural rating scale

\begin{tabular}{|c|c|c|c|}
\hline $\begin{array}{l}\text { Age groups (years) } \\
65 \\
66-74 \\
75-84 \\
85\end{array}$ & $\begin{array}{c}\text { Homes sample } \\
n=684 \\
2 \cdot 8 \% \\
16 \cdot 2 \% \\
46 \cdot 1 \% \\
35 \cdot 0 \%\end{array}$ & $\begin{array}{c}\text { Hospitals sample } \\
n=202 \\
6 \cdot 5 \% \\
26 \cdot 3 \% \\
43 \cdot 2 \% \\
23 \cdot 9 \%\end{array}$ & $x^{2}$ value \\
\hline Items & $\%$ & $\%$ & \\
\hline
\end{tabular}

PHYSICAL DISABILITY

When bathing or dressing requires:

\begin{tabular}{|c|c|c|c|}
\hline No assistance & 11 & 6 & \\
\hline Some assistance & 47 & 33 & \\
\hline Maximum assistance & 42 & 61 & $22 \cdot 41^{* *}$ \\
\hline \multicolumn{4}{|l|}{ h regard to walking: } \\
\hline No signs of weakness & 26 & 34 & \\
\hline Walks slowly or uses a stick & 39 & 24 & \\
\hline $\begin{array}{l}\text { Unable to walk, or if able to walk needs a frame or someone by their side } \\
\text { ncontinent of urine and/or faeces (day or night): }\end{array}$ & 35 & 42 & $14 \cdot 89^{* *}$ \\
\hline Never & 64 & 30 & \\
\hline Sometimes & 20 & 25 & \\
\hline Frequently & 16 & 45 & $96 \cdot 43^{* *}$ \\
\hline \multicolumn{4}{|l|}{ n bed during the day (does not include couch or settee): } \\
\hline Never & 61 & 85 & \\
\hline Sometimes & 30 & 10 & \\
\hline Almost always & 9 & 5 & $36 \cdot 13^{* *}$ \\
\hline \multicolumn{4}{|l|}{ onfused, loses his/her way etc.: } \\
\hline Almost never & 54 & 9 & \\
\hline Sometimes & 30 & 28 & \\
\hline Almost always & 16 & 63 & $102 \cdot 21^{* *}$ \\
\hline \multicolumn{4}{|l|}{ en left to own devices, appearance: } \\
\hline Almost never disorderly & 47 & 24 & \\
\hline Sometimes disorderly & 29 & 28 & \\
\hline Almost always disorderly & 23 & 48 & $56 \cdot 97^{* *}$ \\
\hline
\end{tabular}

APATHY, INACTIVITY

If allowed outside, would:

Never need supervision

Sometimes need supervising

Always need supervision

Helps out in the home/ward:

Often

Sometimes

Never

Keeps occupied in a constructive useful activity (works, reads, has hobbies, etc.): Almost always Sometimes

Almost never ocialises with others:

Does establish good relations with others

Has some difficulty establishing relationships

Has a great deal of difficulty establishing relationships

\section{COMMUNICATION DIFFICULTIES}

Understands what you communicate (speaking, writing or gesturing): Understands almost everything

Understands some of what you communicate

Understands almost nothing of what you communicate

Communicates in any manner (speaking, writing or gesturing):

Well enough to be easily understood at all times

Can be understood sometimes or with difficulty

Can rarely or never be understood for whatever reason 
65

66-74

75-84

85

Homes sample

$n=684$
$2 \cdot 8 \%$

$16 \cdot 2 \%$

$46 \cdot 1 \%$

$35.0 \%$

$\%$

Items
Hospitals sample

$n=202$

$\chi^{2}$ value

$26.3 \%$

$43 \cdot 2 \%$

$23.9 \%$

$21 \cdot 34$

$\%$

SOCIAL DISTURBANCE

Is objectionable to others during the day:

Rarely or never

Sometimes

Frequently

Is objectionable to others during the night:

Rarely or never

Sometimes

Frequently

Accuses others of doing him/her bodily harm or stealing his/her personal

possessions - if sure the accusations are true rate as zero, otherwise rate 1 or 2 : Never

Sometimes

Frequently

Hoards apparently meaningless items (wads of paper, string, scraps, etc.): Never

Sometimes

Frequently

Sleep pattern at night is:

Almost never awake

Sometimes awake

Often awake

SENSORY IMPAIRMENT

Items not scored in the ratings

Can see (or can see with glasses)

Partially blind

Totally blind

$\begin{array}{cc}n=660 & n=129 \\ 78 & 82 \\ 17 & 15 \\ 5 & 3 \\ 80 & \\ 15 & 80 \\ 5 & 15 \\ & 4\end{array}$

No hearing difficulties although uses an aid

Has hearing difficulties which interfere markedly with communication

- $\mathrm{P}<0.01$

$* * P<0.001$

With few exceptions, all the items showed significant differences in rated disability between the social services and hospital groups, and for all but one of the items greater disability was shown in the hospital population. The differences are discussed below under the appropriate heading.

\section{PHYSICAL DISABILITY}

There was a higher proportion of incontinence and confusion in the hospital group. Although approximately the same proportion in each group were occasionally incontinent and were confused at times, a markedly high proportion of the hospital sample had these disabilities nearly all the time whereas more than half of the social services sample did not exhibit such behaviour at all. The hospital sample were more disorderly in appearance if they did not have help; this may be associated with their higher rating for confusion.

Less substantial but still significant differences can be seen in the amount of help needed with bathing, dressing, or walking. The latter shows interesting differences in distribution. Whereas slightly more of the hospital sample needed the maximum assistance with walking, a higher proportion of the hospital than of the social services sample showed no sign of weakness. This difference seems to be accounted for by the fact that more old people in the residential homes showed some difficulty in walking. It is also worth noting that a higher proportion of the residential homes sample were sometimes or always in bed. This may have been due to increased physical frailty or to differences in the policy of the two institutions. Apart from this one item, however, there is evidence of greater overall physical disability in the hospital population.

APATHY, INACTIVITY

Although a high correlation has usually been noted between apathy and physical disability scores, it ${ }^{\circ}$ appears that the differences between the two groups 0 in our study population were somewhat less $\underset{\omega}{N}$ substantial on apathy than on physical disability items. The hospital sample needed a great deal more 
supervision, probably associated with their higher confusion ratings; they were less likely to be involved in helping out or in occupational and social activities. No significant difference was noted, however, in their willingness to do things if asked. It seems that the hospital population may be more apathetic because of lack of motivation or opportunity for activity rather than unwillingness to be involved.

\section{COMMUNICATION DIFFICULTIES}

The hospital sample showed much greater disability in this area in terms both of understanding others and of communicating with them. Again, it seems likely that this is associated with increased mental impairment.

\section{SOCIAL DISTURBANCE}

Although it is sometimes felt that awkward or disruptive behaviour is more prevalent in psychogeriatric patients than in residents in homes for the elderly, less marked differences between the two samples were noted in this area of disability. There was no difference in the proportions of those with objectionable behaviour in the daytime. Although the hospital sample showed more disturbance at night, this seemed to happen 'sometimes' rather than 'frequently'. The hospital patients were more likely to make paranoid accusations at times, but except in a very few cases this was not a major problem in either sample. Sleep disturbance was more frequent in the social services group but nearly half of both samples showed no sleep problems and the difference is accounted for by a significant minority who were frequently awake in the residential home population.

\section{SENSORY IMPAIRMENT}

No differences were noted. The vast majority of subjects in both samples were rated as having no major sensory deficits.

\section{Discussion}

Although it can be seen that in most areas there was greater behavioural disability in the hospital population, the biggest differences, judged by the size of $\chi^{2}$, were in the areas of incontinence, confusion, need for supervision, and communication problems. Thus it appears that the disabilities which particularly characterise the psychogeriatric population and distinguish them from the residential home population are those that reflect the behavioural consequences of cognitive impairment associated with dementia. Other physical abnormalities such as sensory deficits and ambulatory problems do not really discriminate between the two populations. Although overall there is evidence of a higher level of disability in the psychogeriatric population, it is still the case that considerable behaviour impairments exist in the residential home population.

Some caution may be needed in accepting these differences because of the lack of strict comparability between ratings by psychiatric nursing staff and staff in residential homes. Although data presented in the CAPE manual indicate similar levels of interrater item reliability between psychogeriatric ward staff and residential home staff, the possibility remains that the perception of disability is related to social expectation in different environments. This is an intrinsic problem in any comparative study. However, in a previous study, ${ }^{3}$ pre- and post-admission ratings were obtained for 34 residents entering a new residential home. The correlation between the two sets of ratings was $\mathbf{0 . 7 0}$ for the group as a whole, and the mean scores for the two groups who remained stable during the course of the study showed no difference between pre- and post-admission scores. This suggests that the rating scale is not subject to any major bias as a function of different types of raters or environment.

It has been argued that there has been an increase in the average age and disability of the residential home population in recent years." In order to investigate this point, data obtained in 1969 from the residential population reported on by Carstairs and Morrison $^{1}$ was compared with our data.

Three items from the CAPE behavioural rating scale were extracted to correspond to the disability criteria of problems with mobility, incontinence, and mental confusion employed in the Carstairs and Morrison study. These were: item 2, a 3-point rating of ambulancy; item 3, a 3-point rating of incontinence; and item 5, a 3-point rating of confusion. Carstairs and Morrison ${ }^{1}$ refer to 'fully ambulant', 'walks only with aid/chairbound', and 'bedfast'; but clearly those not falling into these categories represent an intermediate/mild disability with walking, which may be identified with a rating of 1 on the behaviour rating scale item 2 . Referring to continence, they employ a grading of 'continent', 'occasionally incontinent', 'incontinent', and 'doubly incontinent'. The first two grades seem to correspond to ratings of 0 and 1 respectively on the behaviour rating scale item 3 , while the latter grades are subsumable into the ' 2 ' rating for this item. Finally, they employ a grading of 'fully alert', 'occasionally muddled', and 'moderately/severely confused', which is taken as corresponding to the scores, 0,1 , and 2 respectively in the behaviour rating scale item 5. The resulting comparison of the Carstairs and Morrison study with our study is presented in 
Table 2 Data from this study compared with the Carstairs and Morrison ${ }^{1}$ samples

\begin{tabular}{|c|c|c|c|c|}
\hline & \multicolumn{2}{|c|}{ Carstairs and Morrison } & \multicolumn{2}{|c|}{ Gilleard, Pattie, and Dearman } \\
\hline & $\begin{array}{l}\text { Homes } \\
(n=232)\end{array}$ & $\begin{array}{l}\text { Hospital } \\
(n=416)\end{array}$ & $\begin{array}{l}\text { Homes } \\
(n=684)\end{array}$ & $\begin{array}{l}\text { Hospital } \\
(n=202)\end{array}$ \\
\hline Fully ambulant & $66.4 \%$ & $47 \cdot 8 \%$ & $26 \%$ & $34 \%$ \\
\hline Intermediate & $24 \cdot 6 \%$ & $22 \%$ & $39 \%$ & $24 \%$ \\
\hline Chairbound/walks only with aid & $9 \%$ & $30 \cdot 3 \%$ & $35 \%$ & $42 \%$ \\
\hline Continent & $76 \cdot 3 \%$ & $44 \%$ & $64 \%$ & $30 \%$ \\
\hline Occasionally incontinent & $19 \cdot 0 \%$ & $28 \%$ & $20 \%$ & $25 \%$ \\
\hline Incontinent & $4 \cdot 7 \%$ & $27 \cdot 6 \%$ & $16 \%$ & $45 \%$ \\
\hline Fully alert & $66.8 \%$ & $17 \cdot 8 \%$ & $54 \%$ & $9 \%$ \\
\hline Occasionally muddled & $21 \cdot 1 \%$ & $21 \cdot 6 \%$ & $30 \%$ & $38 \%$ \\
\hline Moderately/severely confused & $12 \cdot 0 \%$ & $60 \%$ & $16 \%$ & $63 \%$ \\
\hline
\end{tabular}

Table 2. The relevant data were extracted from the south-west Scotland sample presented in Chapter 7 of Carstairs and Morrison.

It is apparent that, compared with the 1969 figures from south-west Scotland, the old people's homes in this study contain (a) fewer ambulant people, (b) more regularly incontinent people, and (c) fewer fully alert people. These figures can be interpreted as indicating marked regional variation, a longitudinal increase in the disability level of residents in such homes, or both. In the hospital samples, the larger number of non-ambulant and incontinent patients, and the smaller number of 'fully alert/not confused' found in our study is thought to be primarily the result of comparing all old people in psychiatric hospitals, as did Carstairs and Morrison, ${ }^{1}$ with those psychogeriatric patients admitted to hospital in their old age. In contrast to the Carstairs and Morrison study, our hospital sample contained patients admitted to hospital only after the age of 60 and thus excluded what is often called the 'graduate' population - that is, patients suffering from chronic functional psychiatric illness who have grown old in hospital. This group exhibit a significantly lower level of behavioural disability. ${ }^{5}$

\section{Conclusion}

The results of this study indicate that the main features differentiating the institutionalised aged in psychiatric hospitals from those in social services homes for the elderly are the behavioural disabilities associated with the cognitive pathology of ageing. The results may reflect the difference between a population composed almost entirely of people $\stackrel{\bar{\Omega}}{\stackrel{2}{2}}$ suffering from dementia and a population at present $\tilde{s}$ composed of a sizeable minority of such people. $\overrightarrow{0}$ Comparison with earlier figures does suggest that there has been a continuing increase in the size of this $\vec{\omega}$ 'minority' within the social services homes for the $\frac{\text { के }}{8}$ elderly and extrapolation of this trend might lead to a prediction that this 'minority' will in the near future become a majority, with serious implications for future plans for the care and management of odid people.

Reprints from Mrs. A. H. Pattie, Principal Clinicăle Psychologist, Clinical Psychology Departme Clifton Hospital, York YO3 6RD.

\section{References}

${ }^{1}$ Carstairs V, Morrison MA. The Elderly in Residential Care. Scottish Health Service Studies No. 19.气 Edinburgh: Scottish Home and Health Department, $\mathbb{D}$ 1971.

${ }^{2}$ Pattie AH, Gilleard CJ. Manual for the Clifton Assessment $\overrightarrow{0}$ Procedures for the Elderly (CAPE). Sevenoaks: Hodder and Stoughton, 1979.

${ }^{3}$ Pattie AH, Gilleard CJ. Admission and adjustment of residents in homes for the elderly. J Epidemiol Community Health 1978; 32: 212-4.

${ }^{4}$ Department of Health and Social Security and Welsh $\stackrel{\bigcirc}{\bigcirc}$ Office. Residential Homes for the Elderly: Arrangements for Health Care. A memorandum of guidance. London: DHSS, 1977.

${ }^{5}$ Gilleard CJ, Pattie AH. The Stockton Geriatric Rating $\delta$ Scale: a shortened version with British normative data. Br J Psychiatry 1977; 131: 90-4. 